\title{
DWPF AMMONIUM ION ANALYSIS (U)
}

by R. E. Eibling

Westinghouse Savannah River Company

Savannah River Site

Aiken, South Carolina 29808

This paper was prepared in connection with work done under Contract No. DE-AC09-89SR18035 with the U. S.

Department of Energy. By acceptance of this paper, the publisher and/or recipient acknowledges the U. S.

Government's right to retain a nonexclusive, royalty-free license in and to any copyright covering this paper, along with the right to reploduce and to authorize others to reproduce all or part of the copyrighted paper. 


\section{DISCLAIMER}

This report was prepared as an account of work sponsored by an agency of the United States Government. Neither the United States Government nor any agency thereof, nor any of their employees, makes any warranty, express or implied, or assumes any legal liability or responsibility for the accuracy, completeness, or usefulness of any information, apparatus, product, or process disclosed, or represents that its use would not infringe privately owned rights. Reference herein to any specific commercial product, process, or service by trade name, trademark, manufacturer, or otherwise does not necessarily constitute or imply its endorsement, recommendation, or favoring by the United States Government or any agency thereof. The views and opinions of authors expressed herein do not necessarily state or reflect those of the United States Government or any agency thereof.

This report has been reproduced directly from the best available copy.

Available to DOE and DOE contractors from the Office of Scientific and Technical Information, P.O. Box 62, Oak Ridge, TN 37831; prices available from (615) 576-8401, FTS 626-8401.

Available to the public from the National Technical Information Service, U.S. Department of Commerce, 5285 Port Royal Rd, Springfield, VA 22161. 
WESTINGHOUSE SAVANNAH RIVER COMPANY SAVANNAH RIVER TECHNOLOGY CENTER

Key Words:
WSRC-RP-92-775

DWPF, Ammonium, Ion Chromatography, Cations

Retention Period: Permanent

CC: L. M. Papouchado, 773-A

C. T. Randall, 704-T

L. F. Landon, 704-T

J. T. Carter, 704-1T

R. A. Jacobs, 704-T

SRTC Records (4)

June 5, 1992

To: $\quad$ E. W. Holtzscheiter, 773-A

From: R. E. Eibling, 704-T Russell P. Eibling

\section{DWPF AMMONIUM ION ANALYSIS (U)}

\section{Introduction and summary}

Ammonium nitrate production during the operation of the Defense Waste Processing Facility (DWPF) has been identified as a major problem. The accumulation of ammonium nitrate deposits in the vent system of the chemical processing cell has substantial safety implications and will require analysis of ammonium ions within DWPF process samples. As a part of the research and development of the DWPF at TNX, an ammonium analysis method developed by Dionex Corporation has been identified and confirmed to provide the required information. This memorandum describes the technical basis of the method, the accuracy and precision of the method, known interferences, and maintenance details.

Based upon experience in the DWPT Analytical Lab at TNX the recommendations are:

Ammonium ion analysis shall be based upon suppressed cation chromatography using the HPIC-CS3 separator column.

- The recommended sample preparation is based upon the analysis of nonradioactive samples and additional work will be necessary to develop a suitable sample preparation for use guring radioactive operation.

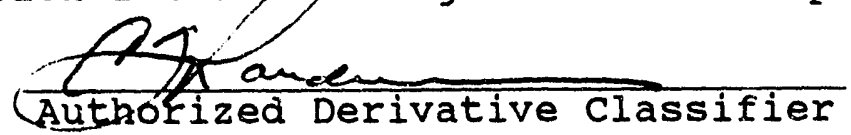


The known interferences are residual hydroxylamine nitrate (HAN) at the 0.5 molar level, and excessively high sodium and potassium ion levels. These excessive levels are not normally expected to be present in DWPF process samples.

- The precision of the method based upon five determinations of the same sample is $\pm 5.7 \%$ using twice the relative standard deviation. The accuracy is better than $92 \%$ again using twice the relative standard deviation from the mean.

- The method can also be used to measure lithium, sodium, potassium and cesium ion concentrations.

Additional work is planned to identify an improved method requiring less maintenance.

\section{Ion Chromatography}

The analysis method used for ammonium ion is based upon ion exchange using a cation resin to separate monovalent cations in a suppressor-based ion chromatograph. Table 1 lists the details of the method along with instructions for producing the eluent and the suppressor regenerant. The analytical column, Cs-3, contains 10 micron particles which have $225 \mathrm{~nm}$ latex partjcles forming a monolayer on the surface of the larger particle. 1 These latex particles contain the sulfonated functional group which provides the ion exchange capacity. Exchange of monovalent cations occurs easily with weak eluents, however, higher valence cations bind tightly to the column requiring strong eluent for elution. The CS-3 column can be used to separate lithium, sodium, ammonium, potassium, rubidium and cesium ions. Figure 1 shows the chromatogram of a $10 \mathrm{ppm}$ ammonium ion solution containing traces of sodium and potassium ions. Peak 1 is sodium ion. Peak 2 is the ammonium ion and peak 3 is the potassium ion. A calibration curve for ammonium ion is shown in Figure 2. Either a quadratic fit or a linear fit can be used across the 1 to $10 \mathrm{ppm}$ calibration range depending on the integrator that is available. The minimum ammonium concentration that can be quantified without sample preconcentration is about $0.5 \mathrm{ppm}$.

The CS-3 column also exchanges +2 and +3 cations which bind tightly to the resin. Examples are the alkaline earth cations such as calcium, magnesium and the transition metal cations. stronger eluents can elute some alkaline earth cations but resolution of the monovalent ions is lost with a stronger eluent. These polyvalent cations accumulate on the column and require periodic flushing with a stronger eluent, 1 molar $\mathrm{HCl}$, to keep the background conductivity at a reasonable level. When flushing the column or the guard column the eluent should not flow through the micromembrane suppressor since some of the metal ions might precipitate when hydroxide ion replaces the chloride ion in the eluent. System cleaning with 1 molar $\mathrm{HCl}$ is necessary every 2 to 
4 weeks depending on the sample load and sample matrices being analyzed based upon experience with prototypic samples at TNX.

\section{Sample Preparation and Interferences}

Sample preparation for nonradioactive samples consists of dilution and filtration. Due to the limited calibration region, dilution requires careful planning to insure the diluted sample is within the calibration curve. Samples are diluted with the eluent. Normal dilution factors are between 10 and 1000 depending on whether the sample is from a low ammonium process (late wash flowsheet) or a high ammonium process (HAN flowsheet). Sample filtration is required to prevent excessive solids accumulation within the ion chromatograph components. Samples should be filtered after dilution with a 0.2 micron or a 0.45 micron nylon filter. Radioactive sample preparation cannot be studied at TNX. Additional work on radioactive sample preparation will be necessary since many of the methods used to remove soluble contamination $(\mathrm{Cs}-137)$ can also remove ammonium ions.

Interferences in ion chromatography can be due to coeluting ions or to excessive concentration of nearby eluting ions causing a loss of resolution. The hydroxylammonium cation, $\mathrm{NH}_{3} \mathrm{OH}^{+}$, has been identified as a coeluting peak. This cation will cause an interference when substantial amounts of HAN are present in the sample. However, the current DWPF sample schedule specifies an ammonium analysis only on aqueous hydrolysis product which normally does not contain a measurable amount of residual HAN. ${ }^{2}$ Experience at TNX indicates that in the HAN process only the prereaction heel sample and the post-catalyst addition sample contain sufficient hydroxylammonium ion to cause problems. If either of thesie samples need ammonium analysis, a special sample preparation procedure still being studied at TNX can be used. In the late wash flowsheet there will be not be any interference since HAN is not used.

The other interference mechanism occurs when the sodium or potassium ion concentration become so large that resolution of the peaks is lost. This can be partially controlled by increasing the dilution at the risk of a loss in sensitivity. Experience with prototypic DWPF samples at TNX indicate that excessive levels of sodium or potassium ions will not be a problem. Problems can occur if sodiun or potassium salts are added to the samples during sample preparation.

\section{Precision and Accuracy}

A study has been made of the accuracy and precision of the ammonium analysis by ion chromatography. To check the arcuracy, two known simulants were prepared that represented HAN aqueous hydrolysis product and Late Wash aqueous hydrolysis product. Each simulant contained the expected concentration of ammonium ion for that process added as ammonium nitrate as well as the 
other expected ionic components. Also analyzed was an actual aqueous hydrolysis product from a HAN process run with irradiated, simulated tetraphenylborate precipitate and a the actual sample spiked with one of the simulants for a recovery calculation. All samples had five separate aliquots diluted and analyzed to check for precision. Results are shown in table 2 . The precision varied between \pm 0.9 and $\pm 2.9 \%$ relative standard deviation. The accuracy on the two know solutions averaged 101.2 $\%$ and $95.6 \%$ with same precision previously cited. Recovery averaged $86.5 \%$ when spiking without a known target concentration. A better recovery can be obtained by insuring that the amount to be spiked $\frac{i}{3} s$ greater than or equal to the amount present in the sample. In general, the method produces accurate and reproducible results.

\section{Documentation}

The precision and accuracy study is recorded in WSRC-NB-90-131. The 772-T ammonium procedure is recorded in $772 \mathrm{~T}-70158$.

\section{References}

1) Paul R. Haddad and Peter E. Jackson, ION CHROMATOGRAPHY PRINCIPLES AND APPLICATIONS, Elsevier Science Publishers $B$. V., Amsterdam, The Netherlands, 1990, page 58.

2) M. L. Mertz, TRANSMITTAL OF REVISED DWPF SAMPLE SCHEDULE (U), OPS-DTC-910022 Revision 1, May 14, 1992.

3) John Keenan Taylor, QUALITY ASSURANCE OF CHEMICAL MEASUREMENTS, Lewis Publishers, Inc., Chelsea, MI, 1987, p 105 . 


\section{Table 1}

Ammonium Analysis Details

Instrument: Ion Chromatograph with Conductivity Detector Equipment :

Guard column:

HPIC-CG3, Dionex Part \# 37025

Separator column:

HPIC-CS3, Dionex Part \# 37024

Suppressor:

Cation Micromembrane (CMMS II)
Dionex Part \# 043021

Reagents:

Eluent:

25 mMolar $\mathrm{HCl}$

0.25 mMolar Diaminopropionic acid Monohydrochloride (DAP.HCl),

Regenerant:

100 mMolar Tetrabutylammonium Hydroxide (TBAOH),

Dionex \# 39602

Flowrates:

Eluent:

Regenerant:
$1 \mathrm{ml} / \mathrm{min}$.

$10 \mathrm{ml} / \mathrm{min}$.

Stock Solution Makeup:

Eluant. Stock:

$250 \mathrm{mM} \mathrm{HCl}, 2.5 \mathrm{mM} \mathrm{DAP} . \mathrm{HCl}$

Fill a 1 Liter volumetric flask half-full with deionized DAP.HCl. Add $21 \mathrm{ml}$ of concentrated $\mathrm{HCl}$ and 0.35 grams DAP.HCl. Dilute with deionized water to the mark.

Eluant:

$25 \mathrm{mM} \mathrm{HCl}, 0.25 \mathrm{mM} \mathrm{DAP.} \mathrm{HCl}$

Dilute $100 \mathrm{ml}$ eluant stock with deionized water to make 1
liter.

Regenerant: $\quad 100 \mathrm{mM} \mathrm{TBAOH}$

Use Dionex already prepared reagent or dilute a known wt $\%$
solution. 


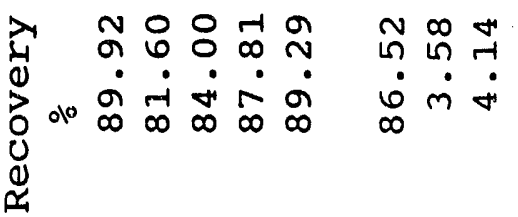

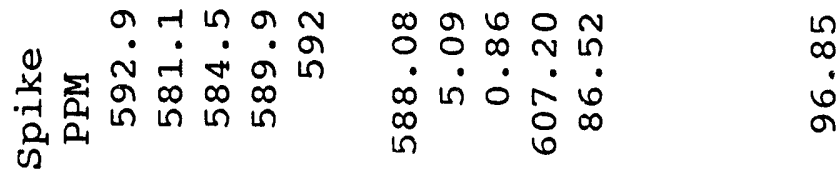

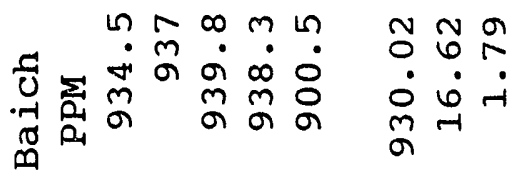

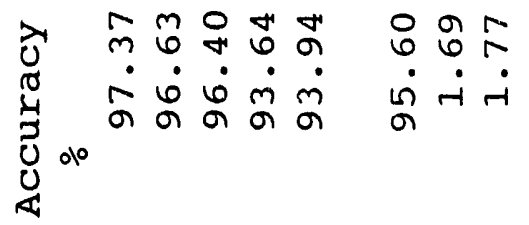

3

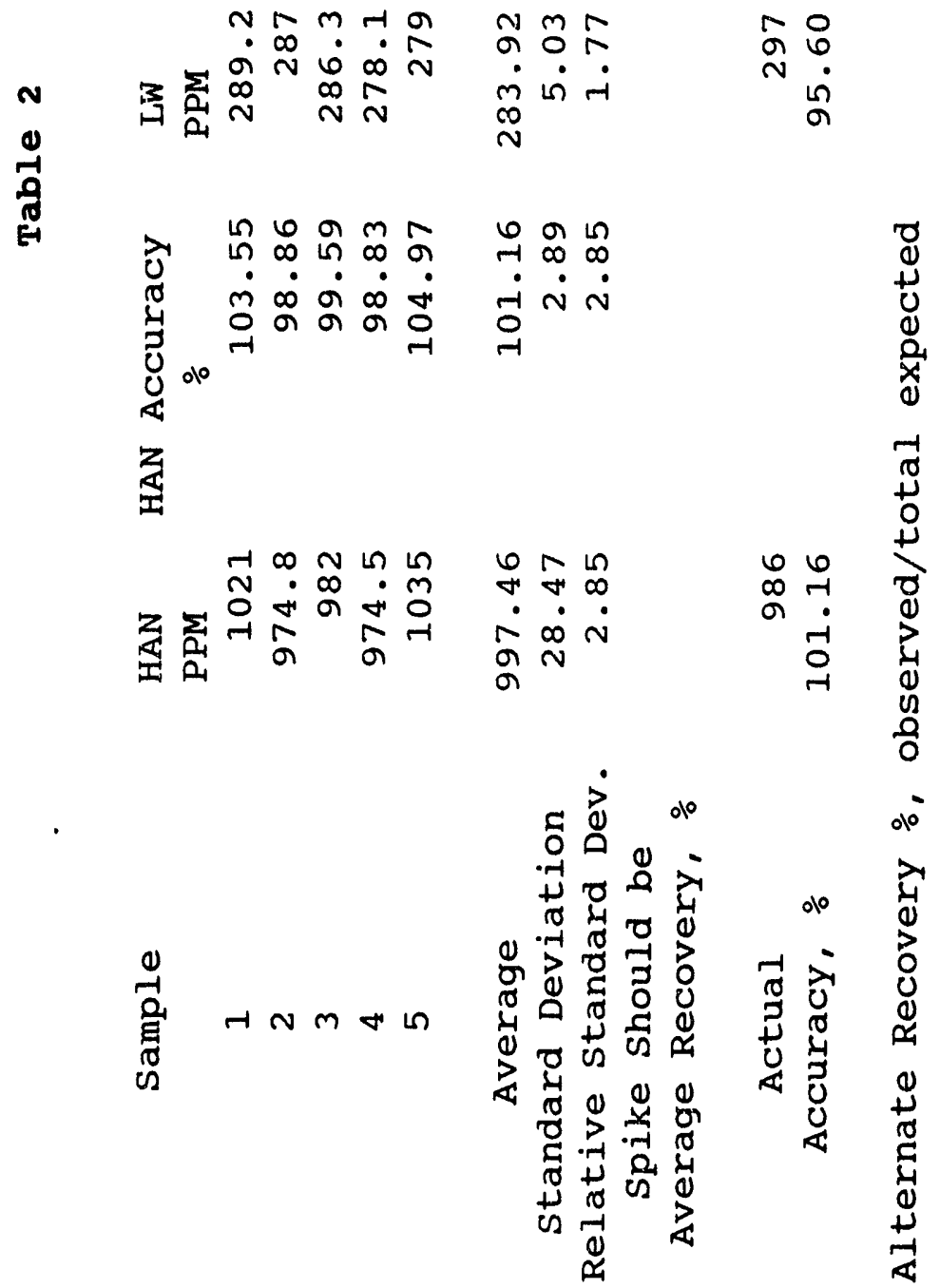


FIGURE 1

File: C:IDXIMETHODICATIONS1.D08 Sam

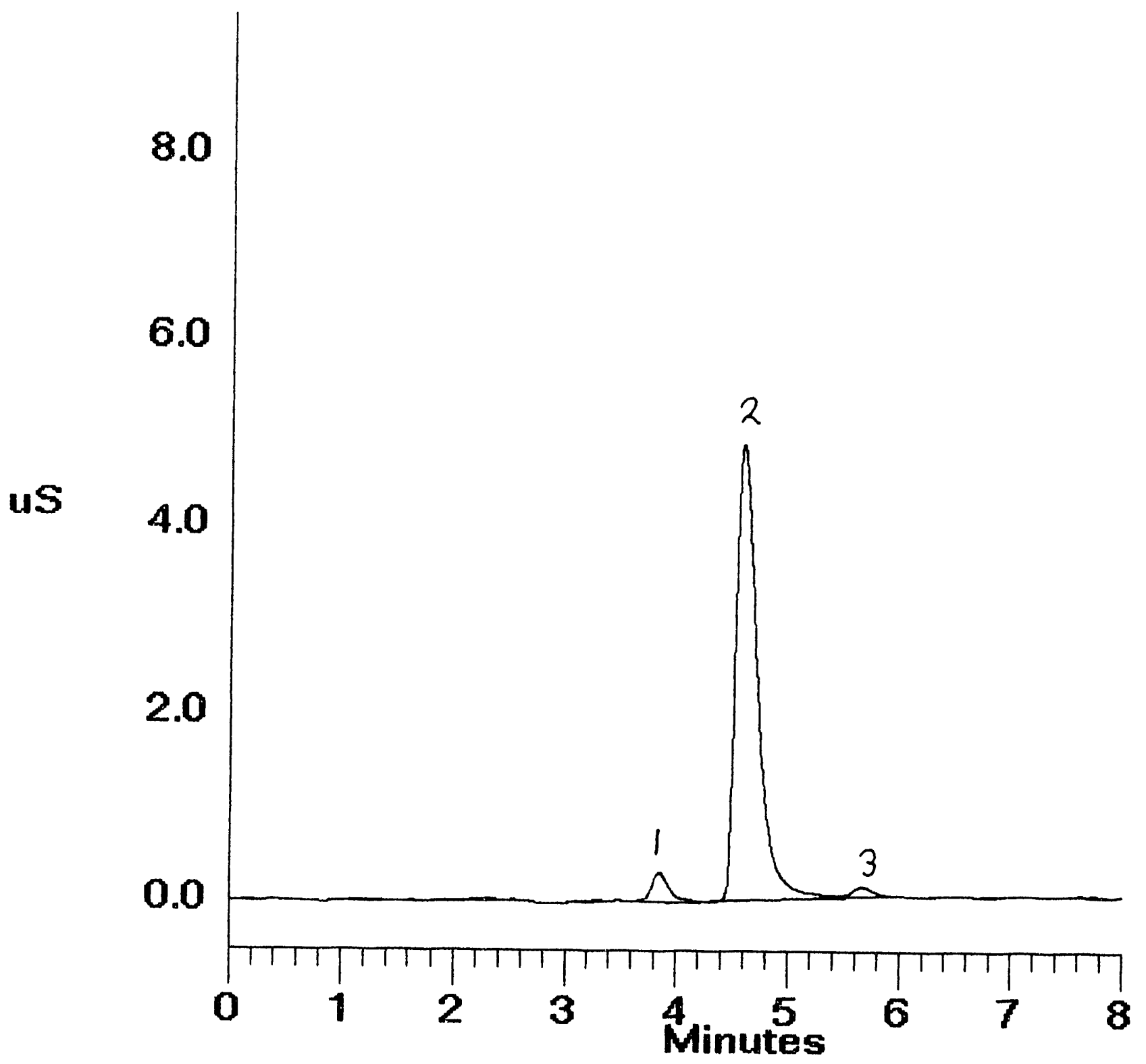


FIGURE 2

Mothod: C: IDXIMETHODICATIONS. MET

Component: AMMONIUM

Fit Type: Quadratic

$r^{\wedge} 2$ : 0.991412

Amt $=(1.6182020-016 \times$ Rosp^2)+

(4.2902090-008*Roep) + -0.0142

Standardization: External

Calibration: Area

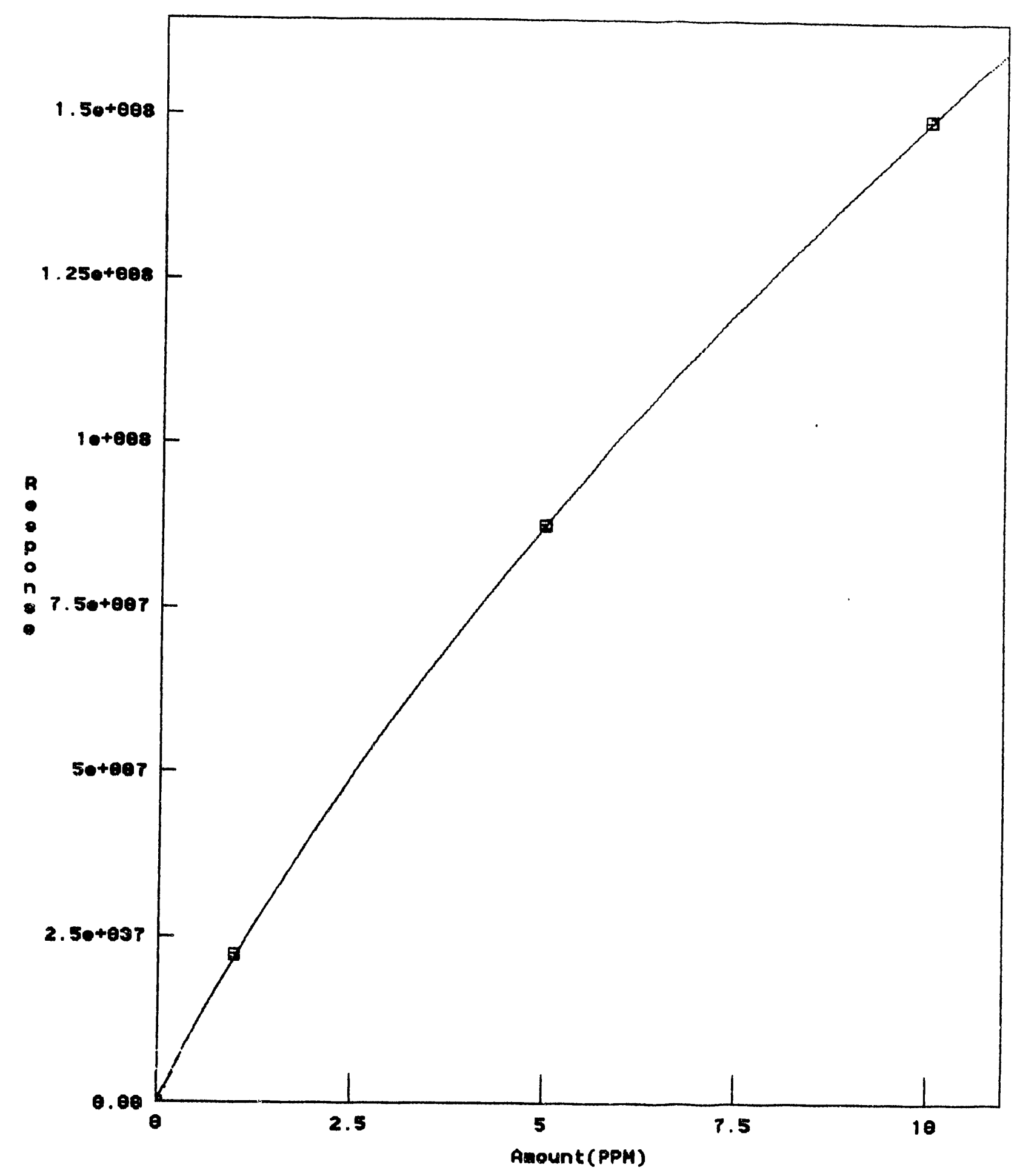



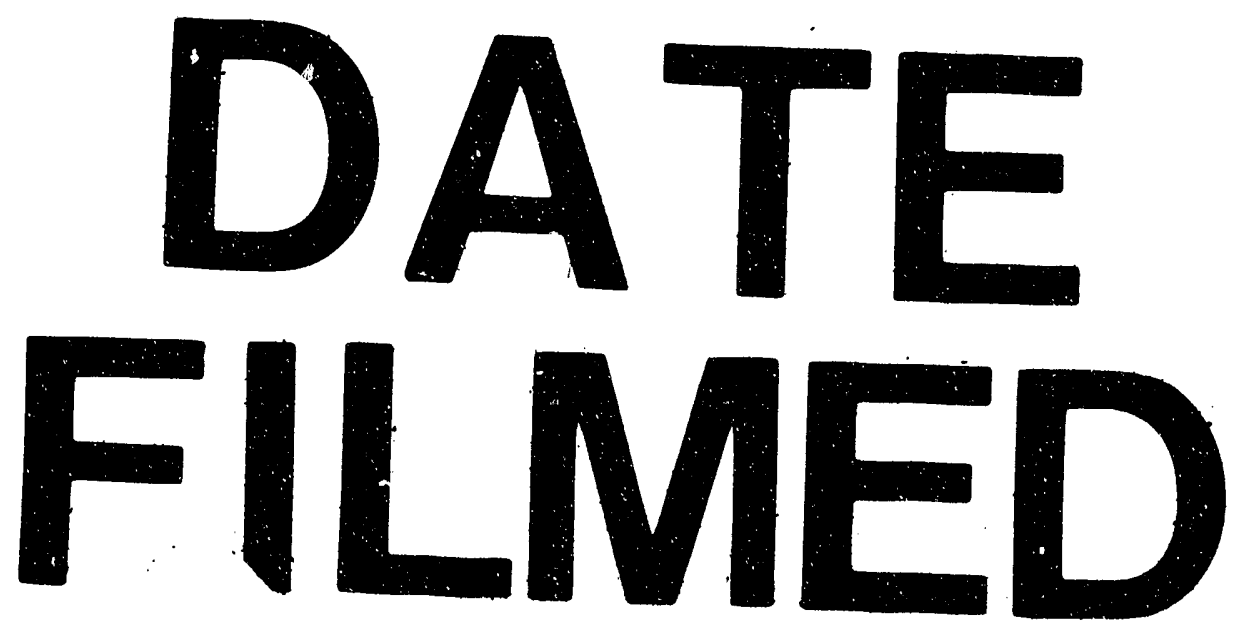

01108193 
